\title{
CD1d expression on chronic lymphocytic leukemia B cells affects disease progression and induces $T$ cell skewing in CD8 positive and CD4CD8 double negative T cells
}

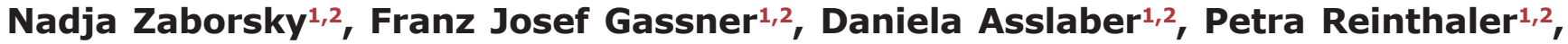 \\ Ursula Denk ${ }^{1,2}$, Sabine Flenady ${ }^{1,2}$, Josefina Piñón Hofbauer ${ }^{1,2}$, Barbara Danner ${ }^{1,2}$, \\ Stefan RebhandI ${ }^{1,2}$, Andrea Harrer ${ }^{3}$, Roland Geisberger ${ }^{1,2}$, Richard Greil ${ }^{1,2}$, Alexander \\ Egle $^{1,2}$ \\ ${ }^{1}$ Laboratory for Immunological and Molecular Cancer Research, Department of Internal Medicine III with Haematology, \\ Medical Oncology, Haemostaseology, Infectiology and Rheumatology, Oncologic Center, Paracelsus Medical University, \\ Salzburg, Austria \\ ${ }^{2}$ Salzburg Cancer Research Institute, Salzburg, Austria \\ ${ }^{3}$ Department of Neurology, Paracelsus Medical University, Salzburg, Austria
}

Correspondence to: Nadja Zaborsky, email: n.zaborsky@salk.at

Keywords: CLL, $T$ cells, $T$ cell skewing, CD1d, CD161

Received: August 25, 2015 Accepted: June 16, $2016 \quad$ Published: July 01, 2016

\section{ABSTRACT}

Chronic lymphocytic leukemia develops within a complex network driven by genetic mutations and microenvironmental interactions. Among the latter a complex interplay with the immune system is established by the clone. Next to a proposed recruitment of support from $\mathrm{T}$ and myeloid cells, potential anti-CLL immune reactions need to be subverted.

By using TCL1 mice as a CLL model, we show that TCR-V $\beta 7^{+}$NK1.1+ T cells are overrepresented in this disease model and constitute a main subset of peripheral $\mathrm{CD}^{+}$cells with biased TCR usage, showing that these cells account for a major part for T cell skewing in TCL1 mice. Moreover, we show that overrepresentation is dependent on CD1d expression in TCL1 mice, implicating that these cells belong to a NKT-like cell fraction which are restricted to antigen presented by the MHC-like surface marker CD1d. Accordingly, we observed a high fraction of $\mathrm{CD}_{161^{+}}$cells within overrepresented T cells in CLL patients and we found downregulation of CD1d on the surface of CLL cells, both in TCL1 mice and patients. Finally, we show that in TCL1 mice, CD1d deficiency resulted in shortened overall survival. Our results point to an interaction between CLL and $\mathrm{CD} 161^{+} \mathrm{T}$ cells that may represent a novel therapeutic target for immune modulation.

\section{INTRODUCTION}

While immunotherapy has been under evaluation for many decades, only recent advances in effectively modulating the patient's immune system have made immunotherapy a promising and appealing strategy in cancer treatment. With its intricate dysregulation of the $\mathrm{T}$ cell system, chronic lymphocytic leukemia (CLL) may be an especially interesting target disease for immunotherapeutic approaches [1]. While the use of immune modulatory drugs such as lenalidomide, and the use of therapeutic antibodies, which target inhibitory immune receptors, were recently shown to partly overcome CLL-associated immune defects in patients and CLL mouse models [2-7], their mode of action, as well as the exact subsets of immune cells targeted by these compounds, still remains elusive.

In this study, we asked whether CD1d restricted $\mathrm{T}$ cells are involved in immune perturbations and $\mathrm{T}$ cell skewing associated with CLL and whether these cells would thus qualify as target for immune reconstitution during therapy. CD1d restricted T cells comprise a T cell subset which is activated by lipid antigen presented by the monomorphic MHC class I like surface molecule CD1d. Generally, these cells are grouped as natural killer (NK) $\mathrm{T}$ cells which constitute a subset of innate $\mathrm{T}$ cells which share features of both innate and adaptive immunity [8-9]. 
NKT cells can respond very rapidly to activation with the production of various cytokines (IFN $\gamma$, IL-4, IL-10, IL-13, IL-17, IL-21) and tumor necrosis factor, thereby enhancing or suppressing immune responses in an MHC independent manner [10]. Unlike MHC class I/II, CD1d presents glycolipid antigens such as $\alpha$-Galactosylceramide ( $\alpha$-GalCer), which can be derived from self or non-self antigenic determinants. Generally, NKT cells are defined by the expression of the NK cell marker NK1.1 (mouse) or CD161 (human) on $\mathrm{CD}^{+} \mathrm{T}$ cells and are divided into type I and type II NKT cells [11]. While type I NKT cells harbor a conserved invariant TCR (thus giving rise to the term invariant or iNKT), preferably consisting of TCR$\mathrm{V} \beta 11$ in combination with an invariant $\mathrm{V} \alpha 24$ in humans and TCR-V $\beta 2$, TCR-V $\beta 7$, TCR-V $\beta 8.2$ in mice, type II NKT cells express a more diverse TCR repertoire [12]. In CLL, CD1d has recently been shown to be aberrantly expressed and its expression level was predictive for a poor clinical outcome [13-14]. Concomitantly, CD56 ${ }^{+}$ $\mathrm{T}$ cells, which are an NKT-like population, were shown to be decreased in progressive CLL patients [15]. In parallel, many $\mathrm{T}$ cell dysfunctions were described to occur in CLL and the occurrence of mono- and oligoclonal $\mathrm{T}$ cell expansions have been observed alongside CLL development in human patients as well as in the TCL1 mouse model for this disease [16-20].

In this study, we aim at a better definition of skewed $\mathrm{T}$ cells in CLL. While our previous results show that in human CLL skewed and overrepresented $\mathrm{CD}^{+} \mathrm{T}$ cells consist of PD- $1^{+}$exhausted T cells [19], our data presented in this manuscript suggest that overrepresented $\mathrm{CD} 8^{+}$as well as CD4/CD8 double negative (DN) T cells frequently belong to the $\mathrm{CD} 161^{+} \mathrm{CD}^{+} \mathrm{T}$ cell compartment. Similar to human CLL, leukemic TCL1 mice show severe TCR-V $\beta$ skewing of $\mathrm{NK} 1.1^{+} \mathrm{CD} 3^{+} \mathrm{T}$ cells, which is abrogated when TCL1 mice are bred on a CD1d deficient background. Finally, CD1d deficiency resulted in reduced overall survival of leukemic mice.

\section{RESULTS}

\section{TCR-V $\beta$ usage is skewed in T cells from TCL1 mice}

We determined TCR-V $\beta$ usage in splenocytes from five fully leukemic TCL1 animals and compared the results to six age-matched wild type mice. We found that $\mathrm{CD}^{+} \mathrm{T}$ cells expressing the TCR-V $\beta 7$ element were dramatically overrepresented in leukemic animals (Figure 1A, 1B; $4.7 \% \pm 0.95 \%$ vs $31.4 \% \pm 13.3 \%$; $p=0.004$; Mann-Whitney test), while no apparent difference was observed for other $\mathrm{V} \beta$-specific $\mathrm{CD}^{+} \mathrm{T}$ cells (Figure 1A, 1B). Notably, V $\beta 7$ overrepresentation was dependent on leukemia development, as young preleukemic animals did not show enrichment of TCR$\mathrm{V} \beta 7 \mathrm{~T}$ cells (Figure 1C). By staining the $\mathrm{V} \beta 7^{+} \mathrm{CD} 3^{+}$
$\mathrm{T}$ cells of sacrificed leukemic mice with antibodies for CD4 and CD8, we further found that these T cells were specifically enriched within $\mathrm{CD}^{+}$and $\mathrm{CD} 4 / \mathrm{CD} 8$ double negative (DN) $\mathrm{T}$ cell fractions (Figure 2A, 2B; for $\mathrm{CD}^{+} \mathrm{T}$ cells: $2.8 \% \pm 0.3 \%$ vs $10.6 \% \pm 9.9 \%$; $p=0.016$; for $\mathrm{CD}^{+} \mathrm{T}$ cells: $10.2 \% \pm 1.7 \%$ vs $52.5 \% \pm 26.8 \%$; $p=0.0004$; for DN cells: $8.9 \% \pm 2.6 \%$ vs $30.6 \% \pm 26.8 \%$, $p=0.0016$; Mann-Whitney test). As V $\beta 7$ is a TCR-V $\beta$ chain commonly used by NKT cells in mice [21], we additionally stained these cells for expression of NK1.1, a marker typically expressed by NK and NKT cells. In comparison to wild type animals, we found that leukemic animals showed a high fraction of the $\mathrm{CD}^{+}$and $\mathrm{DN}$ $\mathrm{V} \beta 7^{+} \mathrm{T}$ cells that was positive for NK1.1 (Figure 2C, 2D; $\mathrm{CD}^{+} \mathrm{V} \beta 7^{+}$cells: $0.5 \% \pm 0.2 \%$ vs $4.8 \% \pm 3.4 \% p=0.005$; $\mathrm{CD}^{+}{ }^{+} \mathrm{CD} 4^{+} \mathrm{V} \beta 7^{+}$cells: $0.2 \% \pm 0.2 \%$ vs $0.9 \% \pm 1.0 \%$ $p=0.084 ; \mathrm{CD}^{+} \mathrm{CD}^{+} \mathrm{V} \beta 7^{+}$cells: $0.5 \% \pm 0.2 \%$ vs $6.6 \% \pm$ $5.3 \% p=0.005 ; \mathrm{CD}^{+} \mathrm{DN} \mathrm{V \beta} 7^{+}: 3.5 \% \pm 3.1 \%$ vs $29.0 \% \pm$ $14.8 \% p=0.002$; Mann-Whitney test).

\section{CD161 cells are enriched in CLL patients}

We next investigated whether in line with our results from TCL1 mice, CLL patients exhibit an increased percentage of $\mathrm{CD} 161^{+}$cells within overrepresented T cell clones. We therefore stained peripheral blood lymphocytes from 18 consecutive non-selected CLL patients using CD161 and TCR-V $\beta$-specific antibodies. In line with our previous results [19], we found that in the peripheral blood of some CLL patients, overrepresented TCR-V $\beta$ specific T cells could be discerned, reaching up to $>80 \%$ occurrence within the peripheral $\mathrm{T}$ cell pool (Figure 3A). Using an arbitrary cut-off of $\geq 25 \%$ occurence of $T$ cells using a particular V $\beta$ element, we found that from 18 consecutive CLL samples analysed, 9 showed at least one overrepresented $\mathrm{CD}^{+}$or DN V $\beta$-specific T cell fraction. In 7 out of these 9 cases with overrepresented T cells, at least one of the respective $\mathrm{T}$ cells exhibited a substantial expression of CD161 which was above the mean CD161 expression levels of all TCR-V $\beta$-specific T cells (CLL \#1-\#7; Figure 3, Supplementary Table S1). Among the remaining two samples, one had a dominant DN TCRV $\beta 20$ fraction at borderline frequency of $24,5 \%$ with clear CD161 expression (CLL \#8, Figure 3) and only one CLL sample showed a dominant $\mathrm{T}$ cell clone without CD161 expression (CLL \#9, Figure 3). Strikingly, within the DN $\mathrm{T}$ cell fraction, all overrepresented cells expressed the TCR-Vß20 element (Figure 3B).

Of note, in contrast to TCL1 mice, we could not detect a general increase of $\mathrm{CD} 161^{+}$or $\mathrm{CD}^{+} 6^{+} \mathrm{T}$ cells in CLL patients compared to healthy volunteers (not shown) and the overrepresented $\mathrm{T}$ cells were not restricted to expression of a particular $\mathrm{V} \beta$ element but showed a diverse set of $\mathrm{V} \beta$ elements with a bias towards V $\beta 20$ usage in DN T cells (Figure 3). Notably, in our small cohort analysed, we did not observe an apparent correlation of 
clinical parameters including CMV seropositivity with the presence or absence of overrepresented CD $161^{+} \mathrm{T}$ cells (Supplementary Table S1).

\section{CD1d expression is altered on CLL samples from patients and from TCL1 mice}

As at least a fraction of $\mathrm{CD} 161^{+} \mathrm{T}$ cells belong to the NKT cell compartment which is restricted to the MHC-like surface protein CD1d, we next determined whether CD1d expression is altered alongside NK1.1 ${ }^{+}$ $\mathrm{T}$ cell augmentation in TCL1 mice. We therefore stained CLL cells from leukemic mice for CD19, CD5 and CD1d and determined CD1d expression levels compared to B cells from wildtype mice by flow cytometry. As shown in Figure 4, we found that leukemic B cells had significantly downregulated surface CD1d as defined by the percentage of cells within the gate for cells stained with an isotype control antibody (CD1d negative CLL cells; Figure 4). Hence, while in wild type animals almost all B cells expressed CD1d (percentage of CD1d negative cells: $2.0 \% \pm 0.2 \%$ ), leukemic cells from TCL1 mice uniformely shifted to a significantly lower CD1d expression (percentage of CD1d negative cells: $20.3 \% \pm$ 24.4\%; Mann Whitney test $p=0.014$ ) (Figure 4A, 4B). To further correlate the frequency of NKT cells with the downregulation of CD1d on CLL cells in the TCL1 mouse model over time, we stained blood samples from several mice at pre-leukemic and leukemic stage and monitored NKT cell levels and CD1d expression. We observed a significant correlation of CD1d negative leukemic cells with the occurrence of $\mathrm{Vb} 7^{+} \mathrm{NK} 1.1^{+} \mathrm{DN}$ $\mathrm{T}$ cells $\left(\mathrm{R}^{2}=0.35 p=0.008\right.$; Supplementary Figure $\left.\mathrm{S} 1\right)$. To test whether these results were recapitulated in human CLL, we stained consecutive non-selected human CLL samples and B cells from healthy controls for expression of CD1d (patient characteristics are given in Supplementary Table S2). In human CLL samples, we observed an even more dramatic downregulation of CD1d, reflected in a significantly higher CD1d negative cell fraction as well as decreased MFI for CD1d in patients compared to healthy volunteers (Figure 4D and
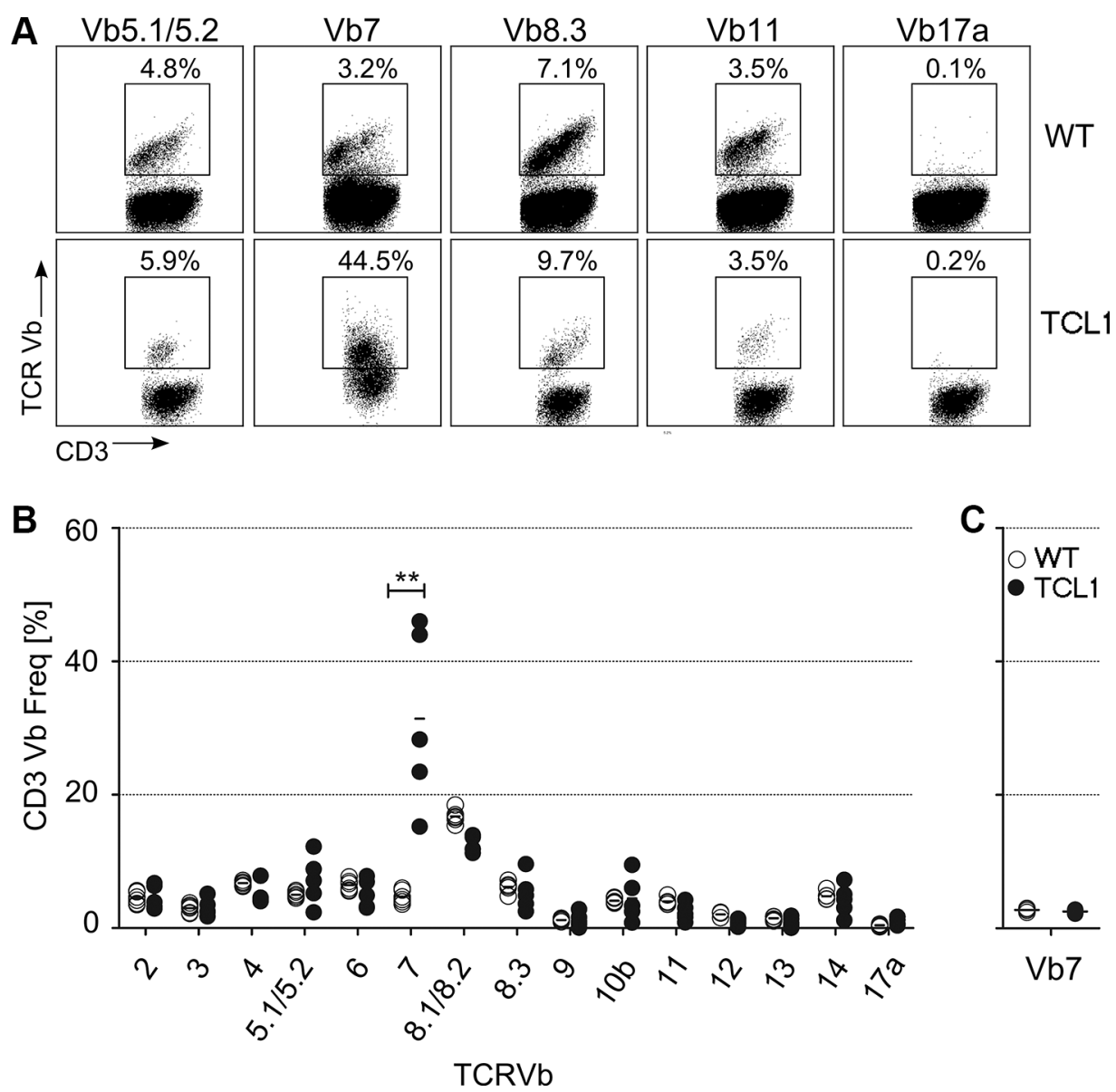

Figure 1: TCR-V $\beta$ usage in the TCL1 CLL mouse model. Splenocytes from sacrificed leukemic TCL1 mice and from agematched wildtype (WT) mice were stained using CD3 and TCR-V $\beta$-specific antibodies. (A) Representative FACS plots for WT and TCL1 mice are shown. (B) Graph showing percentage of $\mathrm{CD}^{+} \mathrm{T}$ cells from leukemic mice, which are expressing the respective $\mathrm{TCR}-\mathrm{V} \beta$ element (WT $n=6$; TCL1 $n=5$ ). (C) Graph showing percentage of CD3 ${ }^{+}$T cells from young preleukemic mice (age $\leq 150$ days), which are expressing the TCR-V $\beta 7$ element $(n=4)$. (Horizontal bars indicate mean percentage). 
Supplementary S2, CD1d negative cells: $8.0 \% \pm 3.2 \%$ vs $63.2 \% \pm 24.8 \%$, Mann Whitney test $p<0.0001$ ). Notably, the appearance of CD1d negative CLL cells significantly correlated with advanced RAI stage and with VLA4 subunit CD49d low expression in our patient cohort (Supplementary Table S3). No association was found for CD1d expression and other clinical parameters including CMV status (Supplementary Tables S2 and S3).

To further functionally characterize CD161/NK1.1 positive $\mathrm{CD}^{+}$and $\mathrm{DN}$ T cells from patients and TCL1 mice, we determined the production of IFN $\gamma$, IL-4 and TNF $\alpha$ of these cells in presence of leukemic cells loaded with or without $\alpha$ GalCer as CD1d restricted lipid antigen. In TCL1 mice, $\mathrm{CD}^{+} \mathrm{T}$ cells expressing these cytokines were specifically enriched within the NK $1.1^{+}$ subset (Supplementary Figure S3A) while in CLL patient samples, $\mathrm{DN}$ and $\mathrm{CD}^{+} \mathrm{T}$ cells exhibited increased cytokine production within the $\mathrm{CD} 161^{+}$fraction, except for IL-4 (Supplementary Figure S3B). In both cases, cytokine production was rather independent from incubation with $\alpha \mathrm{GalCer}$ as lipid antigen.

\section{T cell skewing in leukemic mice is dependent on CD1d expression}

To test whether CLL development as well as concomitant skewing of CD8 and DN T cells was dependent on CD1d, we bred TCL1 mice onto an CD1d-deficient background. We observed that $\mathrm{CD}^{+} \mathrm{CD} 19^{+} \mathrm{CLL}$ cells accumulated in spleens of CD1d $\mathrm{d}^{-/-}$TCL1 mice (Figure 5A).
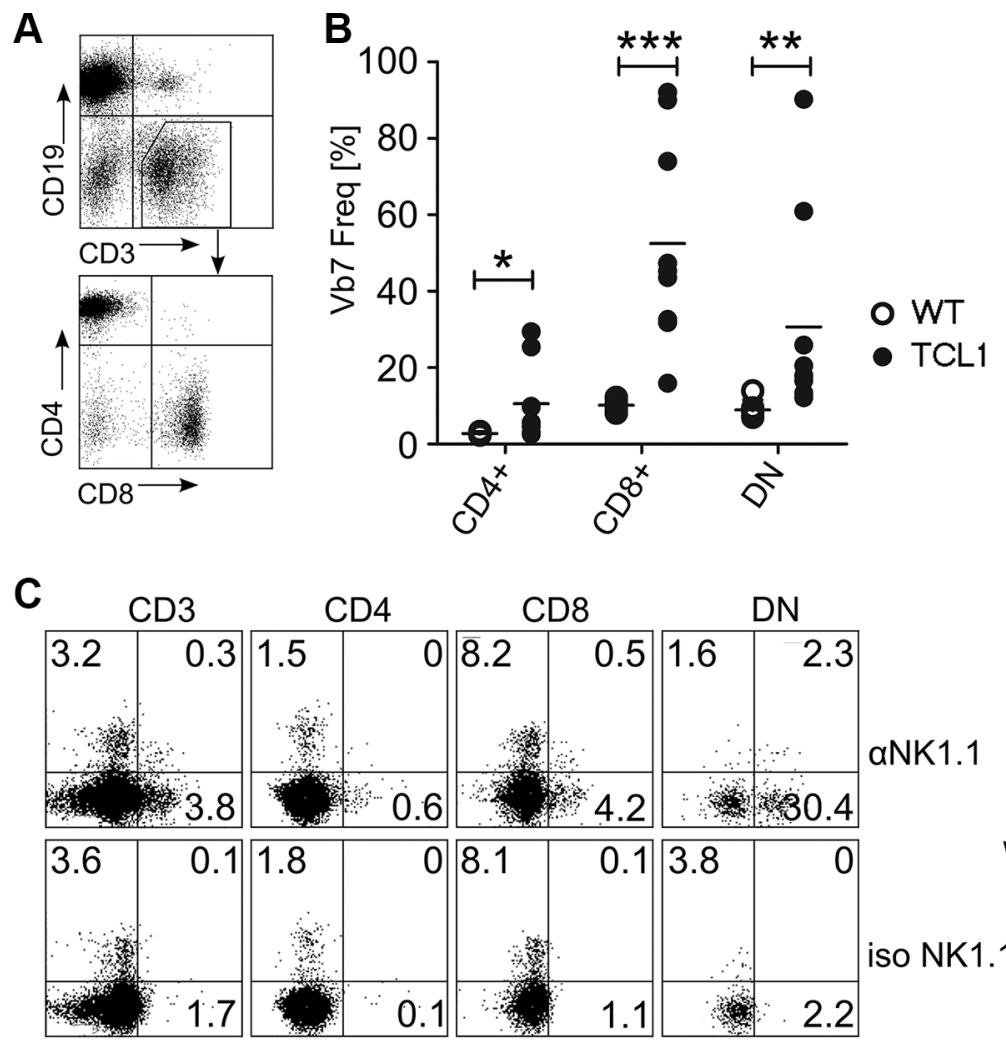

aNK1.1
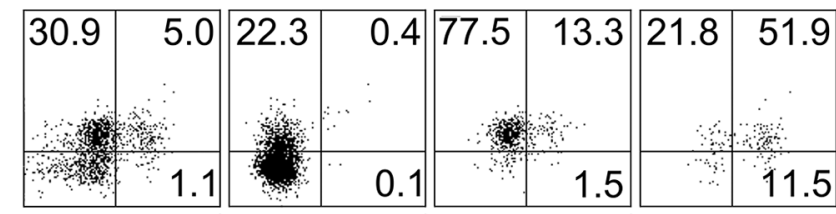

iso NK1.1
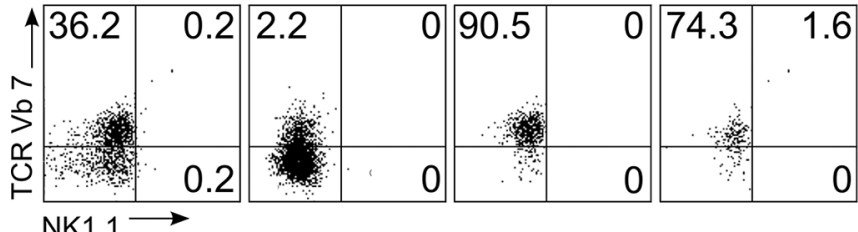

aNK1.1

WT

D

Figure 2: TCR-Vß7 usage in T cell subsets of the TCL1 mouse. $C D 3^{+} V \beta 7^{+} \mathrm{T}$ cells from TCL1 mice were further stained for CD4 and CD8 expression (A, B) and for NK1.1 (C, D). Representative FACS profiles and graphs showing statistical analysis are shown. WT: $n=6$ (B and D), TCL1: $n=9$ (B) or $n=6$ (D). (DN: double negative for CD4 and CD8; iso: staining using an isotype control antibody instead of an anti-NK1.1 antibody). (Horizontal bars indicate mean percentage). 
However, staining splenocytes of sacrificed leukemic mice with TCR-V $\beta$-specific antibodies revealed that the severe $\mathrm{T}$ cell skewing that is usually associated with CLL development in TCL1 mice was absent in CD1d ${ }^{-/}$TCL1 mice, especially within the DN compartment (Figure 5B and Supplementary Table S4). Though a mild skewing was observed in $\mathrm{V} \beta 7^{+} \mathrm{NK} 1.1^{+} \mathrm{CD}^{+}$and $\mathrm{DN}$ subsets of $\mathrm{CD} 1 \mathrm{~d}^{-/-}$TCL1 mice (Figure 5C, 5D), TCR-V $\beta 7$ skewing within the DN subset was significantly different between CD1d deficient and proficient TCL1 mice $(p=0.017$; Supplementary Table S4).

\section{CD1d deficiency shortens overall survival of leukemic mice}

Finally, we tested whether the rate of CLL development is dependent on CD1d expression. We monitored CD1d proficient and deficient TCL1 mouse cohorts for signs of illness and sacrificed mice at standardized humane endpoints. While the median overall survival for CD1d ${ }^{+/+}$TCL1 mice was 398 days $(n=47)$, we observed a significantly shortened overall survival of 340 days for CD1d ${ }^{--}$TCL1 mice $(n=26$; Log-rank Mantel Cox test $p=0.011$; Hazard Ratio 0.352; 95\% Confidence Interval $=0.157-0.788 ;$ Figure 6A). Concomitantly, CD1d $^{-/}$TCL1 mice showed an accelerated leukemia development in the peripheral blood (Supplementary
Figure S4) with no difference in spleen weights at time of sacrifice (Supplementary Figure S5).

To further corroborate that CD1d deficiency accelerates CLL development, we transplanted primary tumors from CD1d proficient and deficient TCL1 mice into wildtype recipient mice. To better assess the influence of CD1d in the transplant setting, we chose a primary TCL1 tumor with high percentage of CD1d expression (Supplementary Figure S6A left panel). We observed that recipient mice transplanted with CD1d ${ }^{-1-}$ TCL1 tumors died earlier from leukemia than mice transplanted with TCL1 tumors (CD1d ${ }^{-/-}$TCL1 $n=4$; TCL1 $n=8$; Log-rank Mantel Cox test $p=0.0009$; Hazard Ratio 61.87 ; $95 \%$ Confidence Interval $=5.405$ to 708.2 ; Figure 6B). Again, we could show that a substantial fraction of CD1d negative CLL cells (from 18\% to $78 \%$ of CLL cells when sacrificed) accumulated over time in peripheral blood of recipients of cohort \#2 transplanted with TCL1 tumors from spleen \#249. Mice which downregulated CD1d on CLL cells (recipients receiving spleen \#249) showed a faster tumor growth and died significantly earlier from leukemia than mice which preserved high CD1d expression (recipients receiving spleen \#250) (TCL1 Tx CD1d ${ }^{\text {high }} n=4$; TCL1 Tx CD1d ${ }^{\text {low }} n=4$; Log-rank Mantel Cox test $p=0.0062$; Hazard Ratio 20.95; 95\% Confidence Interval $=2.376$ to 184.7; Figure 6C and Supplementary S6A, middle and right panel; cohort $2+3$ ). Notably, TCR-V $\beta 7$ skewing, which we observed in TCL1 mice was not pronounced in our transplant
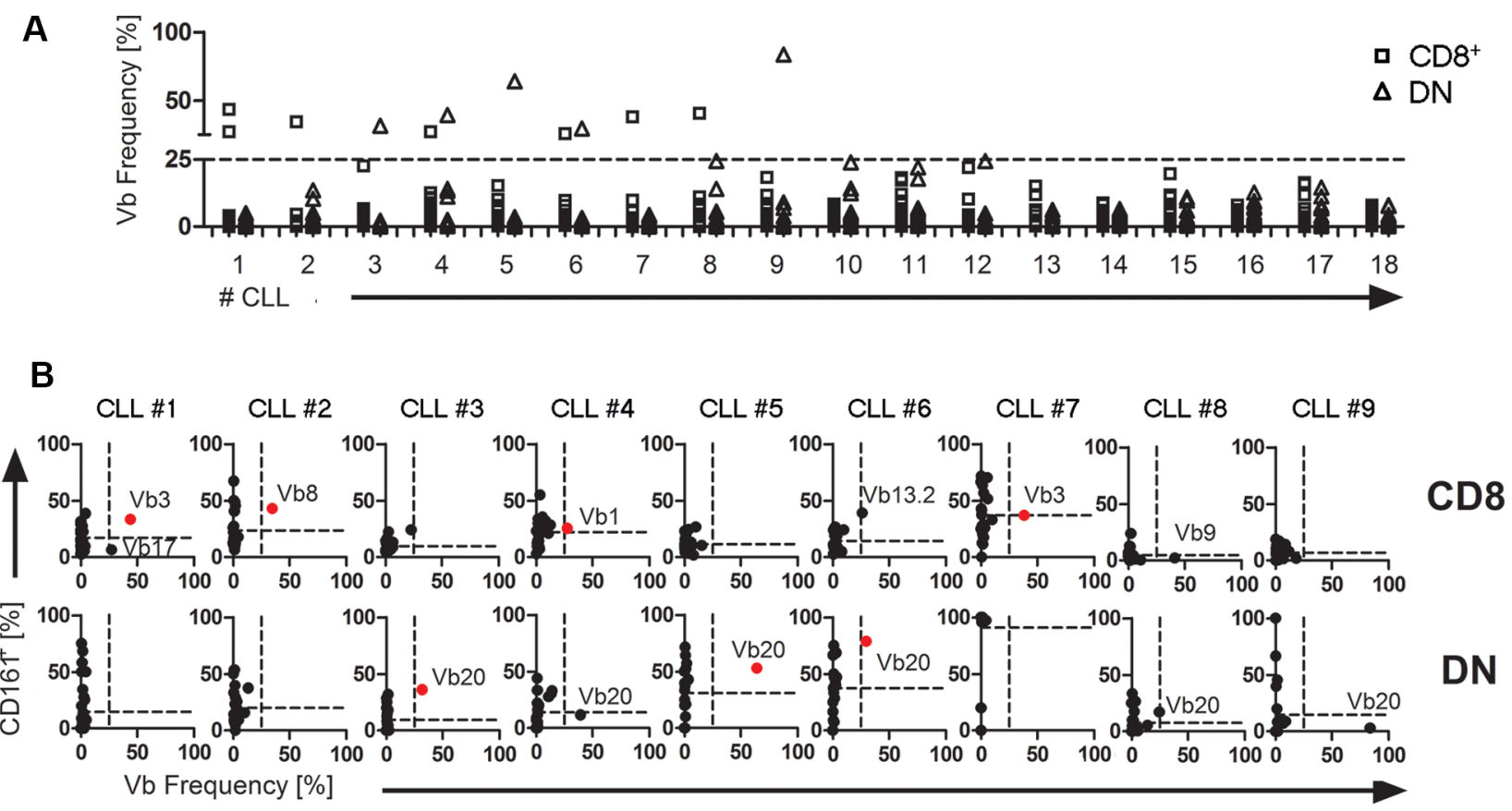

Figure 3: CD161 expression and TCR-V $\boldsymbol{\beta}$ skewing in human CLL. TCR-V $\beta$ usage and CD161 expression within CD $8^{+}$or DN $\mathrm{T}$ cells $\left(\mathrm{CD}^{+}\right)$were quantified by flow cytometry from peripheral blood of 18 CLL patients. (A) The frequency of 24 distinct TCR-V $\beta$ elements within $\mathrm{CD}^{+}$(square) or DN (triangle) T cells $\left(\mathrm{CD}^{+}\right.$) were analysed for $18 \mathrm{CLL}$ patients. A ticked horizontal line at $25 \%$ marks the threshold for overrepresentation. (B) For nine CLL samples with overrepresented T cells, expression values for 24 TCR-V $\beta$ elements were plotted against CD161 expression. A TCR-V $\beta$ usage of more than $25 \%$ was considered overrepresented (the $25 \%$ threshold is indicated by a vertical ticked line within each plot). The mean percentage of CD $161^{+}$cells of all TCR-V $\beta$ subsets is shown as horizontal ticked lines. TCR$\mathrm{V} \beta$-specific T cells within the upper right quadrant (shown in red) are defined as overrepresented T cells with substantial CD161 expression. (the respective overrepresented $\mathrm{V} \beta$ element is indicated within each plot). 
system, possibly due to the increased velocity of tumor growth upon transplantation (Supplementary Figure S6B).

\section{DISCUSSION}

Microenvironmental interactions are important for CLL cells to survive and proliferate [22]. In particular, immune interactions with cognate $\mathrm{T}$ cells are suggested to play a significant role in disease pathogenesis, since it was observed that in CLL, the $\mathrm{T}$ cell compartment exhibits a range of dysfunctions together with the frequent occurrence of overrepresented V $\beta$-specific T cells, which are often oligo- or monoclonal [5, 17, 18, 23-26]. Since these $\mathrm{T}$ cell perturbances were also observed in other B cell Non-Hodgkin lymphomas (NHLs), it is supposed that the $\mathrm{T}$ cell compartment may fundamentally influence disease progression and development of NHLs even though their pathogenesis is extremely heterogeneous [27].

We recently showed that $\mathrm{CD}^{+} \mathrm{T}$ cell skewing in CLL is strongly associated with the BCR mutation status and stereotype, further implicating a likely involvement of antigen in the pathogenesis of CLL [19]. While skewing of $\mathrm{CD}^{+} \mathrm{T}$ cells as a putative CLL-supportive compartment could reflect CLL-induced changes in CLL/CD4 ${ }^{+} \mathrm{T}$ cell immune synapse formation [4, 16, 19, 28], abnormalities in $\mathrm{CD}^{+}$or DN T cells could mirror the attempts of the immune system to cytolytically attack the malignant cells. Hence, a more thorough investigation of skewed $\mathrm{CD}^{+}$ and DN T cells could help to identify putative cancer specific cytolytic T cells, which might be utilized for novel therapeutic approaches.

In this study, we report that in the TCL1 mouse model, overrepresented $\mathrm{CD}^{+} \mathrm{T}$ cells are mainly TCR$\mathrm{V} \beta 7^{+} \mathrm{NK} 1.1^{+}$and $\mathrm{CD}^{+}$or DN. While NK1.1/CD161 is expressed on diverse $\mathrm{T}$ cell subsets [29-30], our observation that this overrepresentation is absent in CD1ddeficient TCL1 mice is a strong evidence that these T cells belong to a CD1d restricted NKT-like subset. Indeed, absence of CD1d on leukemic cells not only abolished TCR-V $\beta 7$ T cell skewing especially within the DN T cell
A

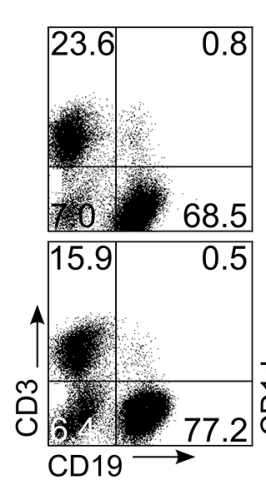

C
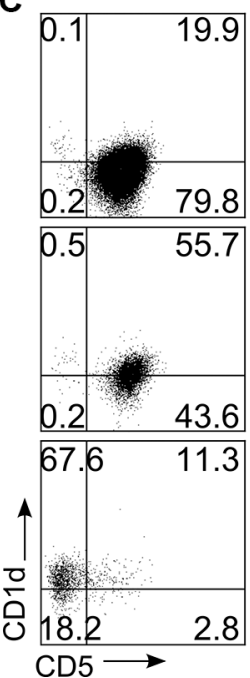

$\mathrm{CD} 19^{+} \mathrm{CD} 3$

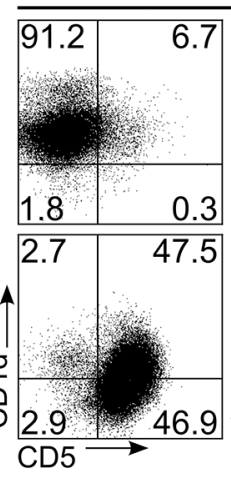

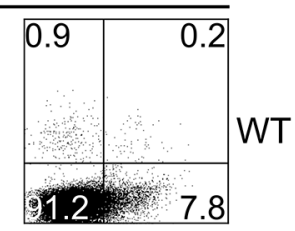

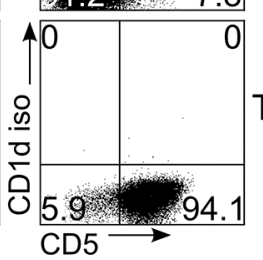

B

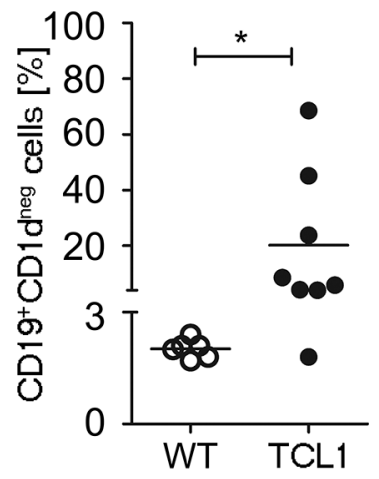

D
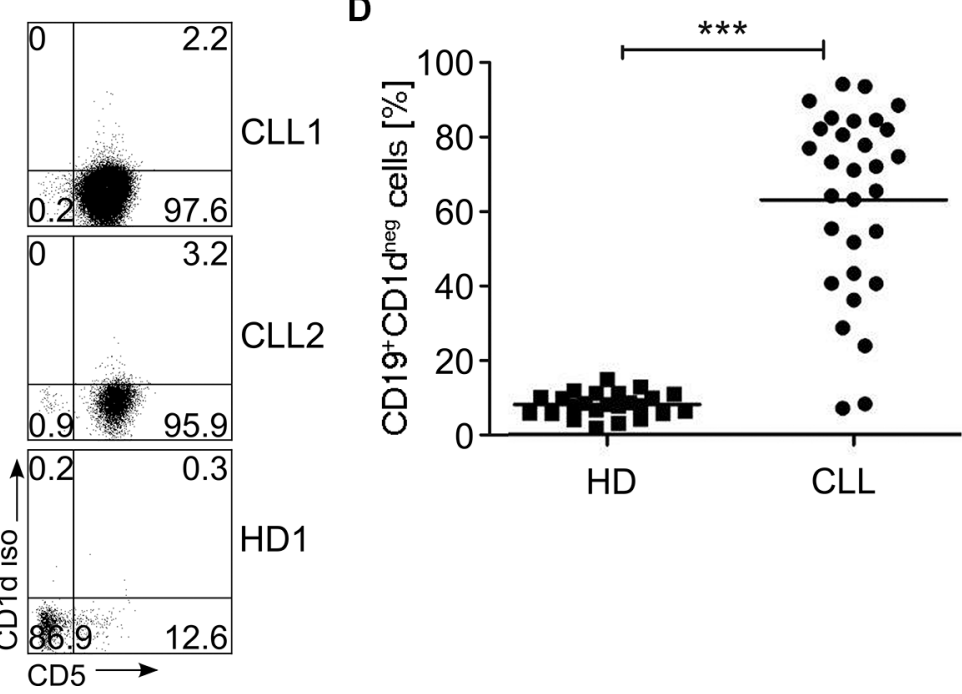

HD

CLL

Figure 4: CD1d expression in TCL1 mice and human CLL samples. CD1d was measured on the surface of TCL1 and wildtype (WT) mouse splenocytes. (A) A representative FACS plot is shown. (B) Shown is the fraction of CD1d negative samples among CD19 ${ }^{+}$ WT B cells $(n=6)$ and the tumor cell population of TCL1 mice $(n=8)$. (C) A representative FACS stain of CD1d on the surface of human CLL samples and B cells from healthy controls (HD) is shown. (D) The fraction of CD1d negative cells for CLL $(n=30)$ and HD $(n=24)$ was determined as shown in (A). (Horizontal bars indicate mean percentage). 
population in TCL1 mice, but also led to reduced overall survival in these mice, implicating CD1d restricted $\mathrm{T}$ cells in CLL defence. Accordingly, TCL1 mice showed downregulation of CD1d on the surface of CLL cells which correlated with the occurrence of TCR-V $\beta 7$ specific $\mathrm{T}$ cells, likely reflecting a continous selective pressure for CLL cells to evade immune recognition through CD1d restricted T cells. In line with that, CLL cells from patients also showed downregulation of CD1d, likely reflecting the same immunologic pressure through CD1d restricted $\mathrm{T}$ cells. Strikingly, our data suggest overexpression of TCR-V $\beta 7$ T cells in TCL1 mice not only in DN and
$\mathrm{CD}^{+} \mathrm{T}$ cells, but to a lesser extent also in $\mathrm{CD}^{+} \mathrm{T}$ cells (Figure 2B). It is conceivable that these overrepresented $\mathrm{CD}^{+}$TCR-V $\beta 7 \mathrm{~T}$ cells also belong to an NKT subset and are CD1d restricted, possibly even to the same lipid antigen. Indeed, CD1d restricted NKT cells are considered to mainly belong to $\mathrm{CD}^{+}$or $\mathrm{DN}$ subsets, although the existence of $\mathrm{CD}^{+} \mathrm{NKT}$ cell populations was reported $[31,32]$. Analogously to our mouse data, expanded CD8 ${ }^{+}$ and DN T cells in CLL patients showed a high percentage of CD161 expression. In mouse and human, NK1.1/ $\mathrm{CD} 161^{+} \mathrm{DN}$ and $\mathrm{CD}^{+} \mathrm{T}$ cells showed robust production of NKT specific cytokines irrespective of stimulation

A

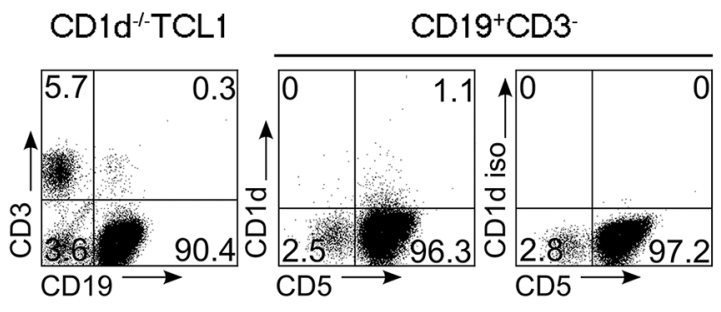

B

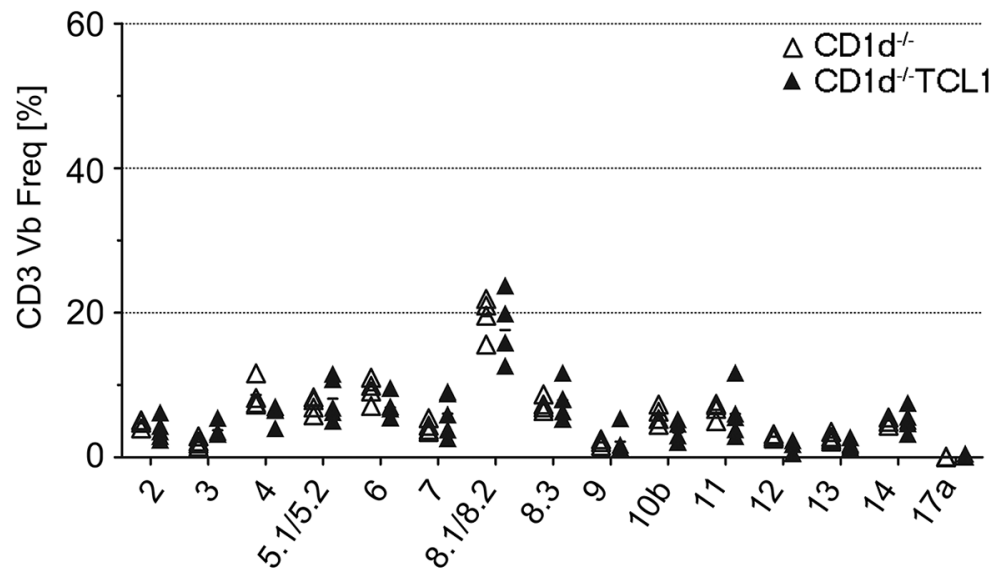

C CD1d ${ }^{-/-T C L 1}$

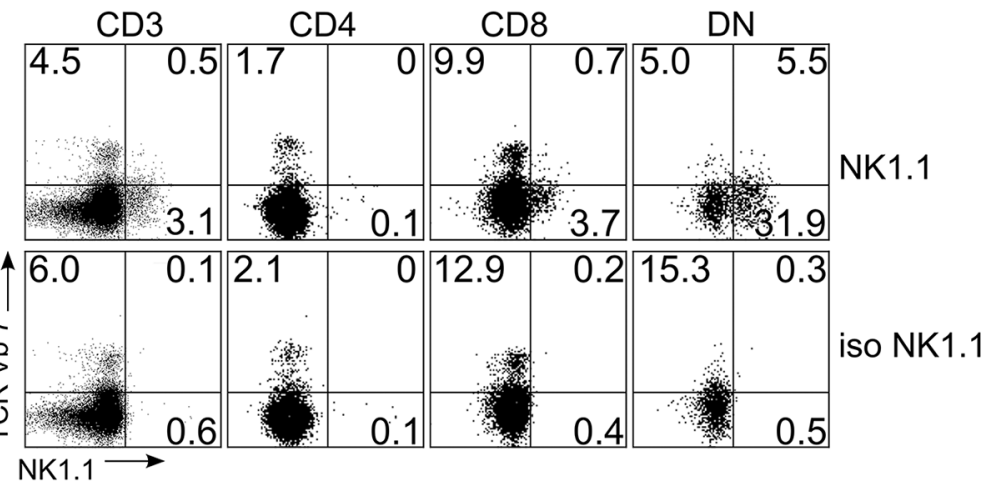

D

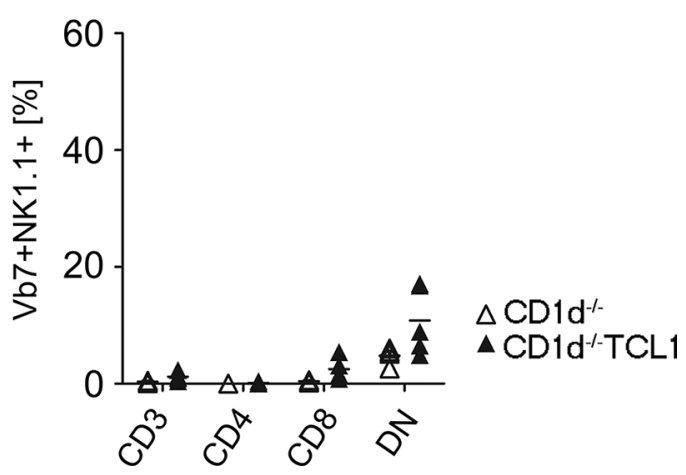

Figure 5: T cell skewing in CD1d knockout mice. (A) CD1d $\mathrm{d}^{-/-}$TCL1 mice generate CLL similar to CD1 $\mathrm{d}^{+/+}$TCL1 mice. Depicted is a representative FACS stain from a CD1d ${ }^{-1-}$ TCL1 mouse on splenocytes stained for CD3, CD19, CD5 and CD1d. On the middle and right FACS plot, CD5 and CD1d expression of gated CD3-CD19+ cells are depicted. (B) TCR-V $\beta$ usage was determined in CD1 ${ }^{-/-}(n=4)$ and $\mathrm{CD}_{1} \mathrm{~d}^{-/-} \mathrm{TCL} 1(n=5)$ mice as described for Figure 1. (C, D) $\mathrm{CD} 3^{+} \mathrm{V} \beta 7^{+} \mathrm{T}$ cells from CD1d ${ }^{-/-} \mathrm{TCL} 1$ mice were further stained for CD4 and CD8 expression and for NK1.1. Representative FACS profiles (C) and graphs (D) are shown. (DN: double negative for CD4 and CD8; iso: staining using an isotype control antibody instead of an anti-NK1.1 antibody). (Horizontal bars indicate mean percentage). 
with $\alpha$ GalCer. This could imply that these cells are not $\alpha$ GalCer-restricted but rather specific for another CLL specific glycolipid antigen presented on CD1d. However, as CD161 expression is not restricted to NKT cells but is associated with diverse T cell subsets [30, 33, 34], further studies are certainly necessary to test antigen specificity and functional capacities, which is beyond the scope of this study.

While we found a clear CD1d dependent overrepresentation of VB7-specific NK1.1 $1^{+} \mathrm{T}$ cells in TCL1 mice, we did not observe V $\beta 7$ skewing despite of CD1d downregulation on leukemic cells in our tumortransplant system, although a general $\mathrm{T}$ cell skewing towards effector-memory $\mathrm{T}$ cells was recently reported upon transplanting TCL1 tumors into wildtype recipients [16]. Probably, the lack of V $\beta 7$ skewing in recipients could be due to the accelerated tumor growth upon transplantation. In other words, clonal expansion of tumor specific NKT cells would be dependent on continous interaction with tumor cells over a long time course, which is only the case in primary TCL1 animals as these mice have approximately a three times longer overall survival. Alternatively, other subsets of the recipient's immune system apart from the NKT cells could take lead in fighting off the tumor, impeding V $\beta 7$ skewing in the transplant system.

In contrast to our TCL1 mice, we could not discern a general increase of CD161 ${ }^{+} \mathrm{T}$ cells in CLL patients. In addition, a recent report showed that $\mathrm{CD}^{+} 6^{+}$NKT-like cells are decreased in progressive CLL patients [15]. However, measuring NKT subsets based on expression of surrogate markers such as CD56 or CD161 could well yield opposing results. In addition, though we did not observe increased $\mathrm{CD} 161^{+} \mathrm{T}$ cells in patients, we noticed a striking overrepresentation of TCR-V $\beta 20$ specific DN T cells with substantial CD161 expression in this study. While we could not find reports on this particular $\mathrm{T}$ cell subset in the literature, it has been shown that V $\beta 20$ specific T cells have a restricted CDR3 length distribution in children with acute B lymphoblastic leukemia [35]. Future studies will certainly be necessary to more thoroughly define CDR3 sequences as well as cytokine profile and functional capacities of these $\mathrm{T}$ subset to precisely elucidate their role in CLL pathogenesis.

Concomitant with the high percentage of CD161 expression on overrepresented $\mathrm{T}$ cells, CD1d was markedly downregulated in human CLL samples, which might reflect a strategy for immune evasion from CD1d dependent cytolytic attack. Notably, downregulation of CD1d was also observed in murine CLL. As we suspect these T cells to be CLL-specific, it will be important to evaluate the feasibility of utilizing these cells in clinical strategies to control CLL. According to a previous report suggesting $\mathrm{CD}^{+} \mathrm{CD}^{+} 6^{+} \mathrm{NKT}$ cells to be used for CLL therapy after in vitro augmentation [36], it will be important to evaluate TCR-V $\beta$-specific $\mathrm{CD} 3^{+} \mathrm{CD} 161^{+}$ cells for that purpose. In particular, it will be interesting to test cytotoxicity of these cells upon modulation of CD1d on CLL cells and whether restoration of CD1d on CLL in vivo could be accomplished by immunomodulatory drugs such as lenalidomide, which was recently shown to reconstitute several immune dysfunctions associated with CLL $[1,3,5,6]$. Of note, it would be interesting to search for $\mathrm{CD}_{161^{+}}$cells or NKTlike phenotypes within overrepresented $\mathrm{T}$ cell subsets in other B cell NHL.

In conclusion, we found $\mathrm{NK} 1.1 / \mathrm{CD} 161^{+}$cells in a substantial fraction of TCR-V $\beta$-specific overrepresented $\mathrm{T}$ cells in CLL and can show that loss of CD1d in the mouse model significantly accelerates disease development. Thus the observed downmodulation of CD1d in murine and also in human CLL represents a plausible mechanism for immune escape from a CD1d dependent cytolytic $\mathrm{T}$ cell attack. In this scenario modulation of CD1d may be a novel goal for CLL immunotherapy approaches.
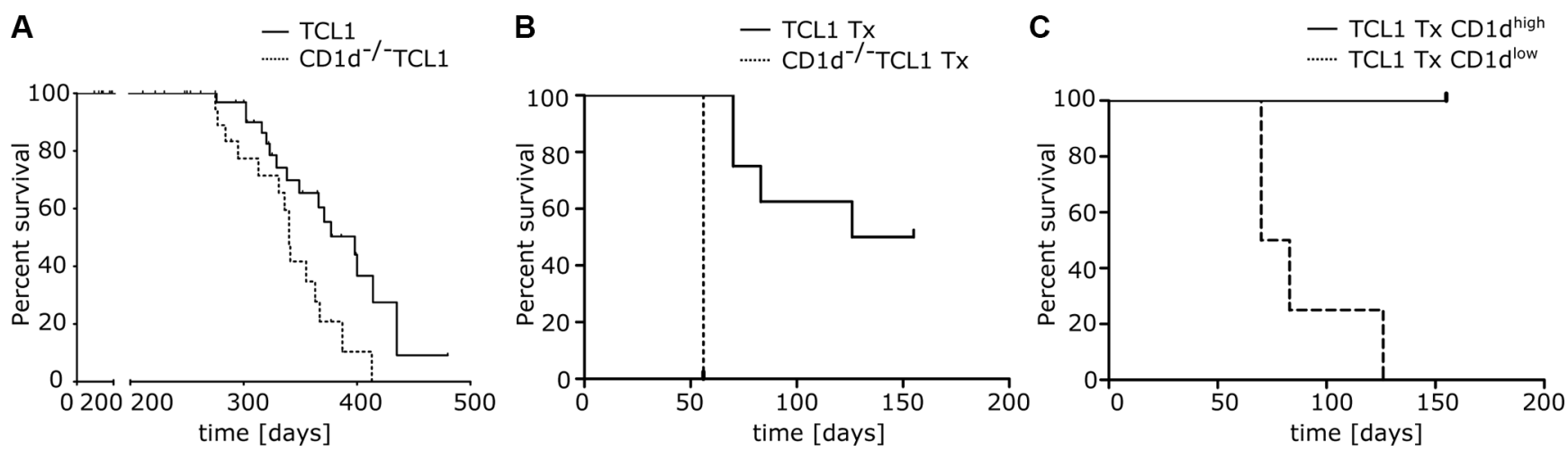

Figure 6: Overall survival in CD1d proficient and deficient TCL1 mice. (A) CLL development was monitored in CD1 $\mathrm{d}^{+/+}$TCL1 $(n=47)$ and CD1d ${ }^{-/}$TCL1 $(n=26)$ mice and overall survival was assessed for both cohorts. (B) Overall survival of wildtype recipient mice transplanted (Tx) with TCL1 and CD1d ${ }^{-/-}$TCL1 tumors (CD1d ${ }^{-/}$TCL1 Tx $n=4$ and TCL1 Tx $\left.n=8\right)$. (C) Overall survival of wildtype recipient mice transplanted with TCL1 tumors shown in (B; TCL1 Tx). Mice were grouped in two cohorts based on CD1d expression in peripheral blood (TCL1 Tx CD1 ${ }^{\text {high }} n=4$ and TCL1 Tx CD1d ${ }^{\text {low }} n=4$ ) and percent survival was calculated. 


\section{MATERIALS AND METHODS}

\section{CLL samples}

Peripheral blood from CLL patients was collected at our medical department upon informed consent in accordance with the Declaration of Helsinki and upon approval by the ethics committee of Salzburg, Austria (Ref. No. 415-E/1287/4-2011 and 415-E/1287/8-2011). Peripheral blood from age-matched healthy controls was collected at the stroke prevention center at the department of neurology upon informed consent. The patients' characteristics are shown in Supplementary Tables S1 and S2. The determination of prognostic markers was performed as previously described [37].

\section{Mice}

Animal experiments were performed under approval from the central Austrian animal ethics committee. The licenses for animal experimentation, BMWF 66.012/0009-II/3b/2012 and 20901-TGV/52/11-2012, are held by Alexander Egle. TCL1 mice on C57BL/6 background $[16,38]$ or backcrossed to CD1d-deficient mice, which lack type I NKT cells (Jackson Laboratories, Bar Harbor, ME, USA; Stock Number: 008881) were followed for signs of illness and killed by $\mathrm{CO}_{2}$ suffocation at humane endpoints. Spleen samples for flow cytometric analysis were collected and subsequently stained using the respective antibodies. Transplanation of murine tumor cells into congenic immune competent wildtype recipient mice was performed as previously described [16]. In brief, splenocytes from TCL1 mice and CD1d ${ }^{-/-}$TCL1 mice were transferred intraperitoneally into recipients (one tumor into four recipients). Leukemia development, CD1d expression, V $\beta 7$ skewing and overall survival was monitored in those mice where transplanatation of tumor cells was successful (ie recipients in which leukemic cells were detectable by flow cytometry on tail vein blood from at least one single bleeding post transplantation).

\section{Flow cytometry}

For the characterization of lymphocytes from CLL patients and healthy donors, fresh blood samples were stained prior to erythrocyte lysis using FACS lysing solution (Becton Dickinson). The following antibodies were used: CD3 FITC, CD19 Brilliant Violet (both Biolegend), CD5 PE-Cy5 (Beckman Coulter), CD8 Pacific Orange (Invitrogen), CD4 PE-Cy7, CD1d PE, CD161 eFluor 450, CD56 PerCP-eFluor 710, CD3 AlexaFluor 700, TCR Va24 APC (all eBioscience).

For determination of TCR-V $\beta$ usage, cells were stained with the IOTest ${ }^{\circledR}$ Beta Mark Kit (Beckman Coulter) where eight sets of three TCR-V $\beta$ - specific antibodies (each set comprises a FITC, PE and FITC/ PE conjugated antibody) are combined in a single test.
Samples were stained together with antibodies for CD3, CD4, CD8, TCR Va24, CD56 and CD161.

Murine samples (splenocytes of sacrificed mice) were stained using the following antibodies: TCR-V $\beta$ FITC (TCR-V $\beta$ screening panel, BD Pharmingen), CD3 PE, CD1d PE (all BD Pharmingen), CD4 PE-Cy5, CD19 PE-Cy7, CD8 Pacific Blue, CD3 AlexaFluor 700, CD5 PE-Cy5, CD8 PE-Cy7, CD19 Pacific Blue (all Biolegend), NK1.1 PE-Cy7, CD3 FITC (eBioscience).

For intracellular detection of cytokines, the cells were stimulated with $100 \mathrm{ng} / \mathrm{ml} \alpha \mathrm{GalCer}$ (Biovision) for the indicated time and stained using Intracellular Fixation/ Permeabilization Buffer Set and monensin (eBioscience) according to the instructions of the manufacturer. The following antibodies were used:

mouse: anti-Mouse IFN $\gamma$ PerCP-Cy5.5, anti-Mouse

IL-4 PE, anti-Mouse TNF $\alpha$ APC (all eBioscience).

human: anti-human IFN $\gamma$ FITC, anti-human IL-4 PE, anti-human TNF $\alpha$ APC (all eBioscience).

Samples were measured on a Gallios flowcytometer (Beckman Coulter) and analysed using Kaluza 1.2 software (Beckman Coulter).

\section{Statistics}

All statistical analyses were performed using GraphPad Prism 5.02 Software or IBM SPSS Statistics 21 software. Overall survival curves were plotted by KaplanMeier and the survival distributions of the different cohorts were compared using log-rank (Mantel-Cox) test. Mann-Whitney or Student's $t$-tests were used as indicated to analyse significance.

\section{ACKNOWLEDGMENTS AND GRANT SUPPORT}

This work was supported by the SCRI-LIMCR, the Province of Salzburg, the City of Salzburg, grants from the Austrian Science Fund (FWF; Hertha Firnberg Grant T516-B13 to N. Zaborsky, Project P24100 to R. Greil), and a grant from the Paracelsus Medical University (PMU Grant E-12/16/084-EGG to A. Egle). In addition, A. Egle's work in CLL is supported by DACH grant FOR-2036 I-1299.

\section{CONFLICTS OF INTEREST}

Authors declare there are no competing financial interests in relation to the work described.

\section{REFERENCES}

1. Riches JC, Gribben JG. Immunomodulation and immune reconstitution in chronic lymphocytic leukemia. Semin Hematol. 2014; 51:228-234. 
2. McClanahan F, Hanna B, Miller S, Clear AJ, Lichter P, Gribben JG, Seiffert M. PD-L1 Checkpoint Blockade Prevents Immune Dysfunction and Leukemia Development in a Mouse Model of Chronic Lymphocytic Leukemia. Blood. 2015.

3. Gassner FJ, Zaborsky N, Neureiter D, Huemer M, Melchardt T, Egle A, Rebhandl S, Catakovic K, Hartmann TN, Greil R, Geisberger R. Chemotherapy-induced augmentation of $\mathrm{T}$ cells expressing inhibitory receptors is reversed by treatment with lenalidomide in chronic lymphocytic leukemia. Haematologica. 2014; 99:67-69.

4. Gorgun G, Ramsay AG, Holderried TA, Zahrieh D, Le DR, Liu F, Quackenbush J, Croce CM, Gribben JG. E(mu)-TCL1 mice represent a model for immunotherapeutic reversal of chronic lymphocytic leukemia-induced T-cell dysfunction. Proc Natl Acad Sci USA. 2009; 106:6250-6255.

5. Ramsay AG, Johnson AJ, Lee AM, Gorgun G, Le DR, Blum W, Byrd JC, Gribben JG. Chronic lymphocytic leukemia $\mathrm{T}$ cells show impaired immunological synapse formation that can be reversed with an immunomodulating drug. J Clin Invest. 2008; 118:2427-2437.

6. cebes-Huerta A, Huergo-Zapico L, Gonzalez-Rodriguez AP, Fernandez-Guizan A, Payer AR, Lopez-Soto A, Gonzalez S. Lenalidomide induces immunomodulation in chronic lymphocytic leukemia and enhances antitumor immune responses mediated by NK and CD4 T cells. Biomed Res Int. 2014; 2014:265840.

7. Gassner FJ, Zaborsky N, Catakovic K, Rebhandl S, Huemer M, Egle A, Hartmann TN, Greil R, Geisberger R. Chronic lymphocytic leukaemia induces an exhausted $\mathrm{T}$ cell phenotype in the TCL1 transgenic mouse model. Br J Haematol. 2015.

8. ho-Fernandez E, Brigl M. The Extended Family of CD1d-Restricted NKT Cells: Sifting through a Mixed Bag of TCRs, Antigens, and Functions. Front Immunol. 2015;6:362.

9. Bollyky PL, Wilson SB. CD1d-restricted T-cell subsets and dendritic cell function in autoimmunity. Immunol Cell Biol. 2004; 82:307-314.

10. Rossjohn J, Pellicci DG, Patel O, Gapin L, Godfrey DI, Recognition of CD1d-restricted antigens by natural killer $\mathrm{T}$ cells. Nat Rev Immunol. 2012; 12:845-857.

11. Godfrey DI, MacDonald HR, Kronenberg M, Smyth MJ, Van KL, NKT cells: what's in a name? Nat Rev Immunol. 2004; 4:231-237.

12. Delovitch TL, The "End of the beginning" of the immunobiology of iNKT cells in health and disease. Int Rev Immunol. 2007; 26:1-3.

13. Anastasiadis A, Kotsianidis I, Papadopoulos V, Spanoudakis E, Margaritis D, Christoforidou A, Gouliamtzi S, Tsatalas C. CD1d expression as a prognostic marker for chronic lymphocytic leukemia. Leuk Lymphoma. 2014; 55:320-325.

14. Bojarska-Junak A, Hus I, Chocholska S, Tomczak W, Wos J, Czubak P, Putowski L, Rolinski J. CD1d expression is higher in chronic lymphocytic leukemia patients with unfavorable prognosis. Leuk Res. 2014; 38:435-442.

15. Jadidi-Niaragh F, Jeddi-Tehrani M, Ansaripour B, Razavi SM, Sharifian RA, Shokri F. Reduced frequency of NKT-like cells in patients with progressive chronic lymphocytic leukemia. Med Oncol. 2012; 29:3561-3569.

16. Hofbauer JP, Heyder C, Denk U, Kocher T, Holler C, TrapinD, Asslaber D, Tinhofer I, Greil R, Egle A. Development of CLL in the TCL1 transgenic mouse model is associated with severe skewing of the T-cell compartment homologous to human CLL. Leukemia. 2011; 25:1452-1458.

17. Rezvany MR, Jeddi-Tehrani M, Osterborg A, Kimby E, Wigzell H, Mellstedt H. Oligoclonal TCRBV gene usage in B-cell chronic lymphocytic leukemia:Major perturbations are preferentially seen within the CD4 T-Cell subset. Blood. 1999; 94:1063-1069.

18. Rezvany MR, Jeddi-Tehrani M, Wigzell H, Osterborg A, Mellstedt H. Leukemia-associated monoclonal and oligoclonal TCR-BV use in patients with B-cell chronic lymphocytic leukemia. Blood. 2003; 101:1063-1070.

19. Zaborsky N, Holler C, Geisberger R, Asslaber D, Gassner FJ, Egger V, Pinon-Hofbauer J, Kocher T, Hartmann TN, Greil R, Egle A. B cell receptor usage correlates with the sensitivity to CD40 stimulation and the occurrence of CD4+ T cell clonality in chronic lymphocytic leukemia. Haematologica. 2015.

20. Goolsby CL, Kuchnio M, Finn WG, Peterson L. Expansions of clonal and oligoclonal $\mathrm{T}$ cells in B-cell chronic lymphocytic leukemia are primarily restricted to the $\mathrm{CD} 3(+)$ CD8(+) T-cell population. Cytometry. 2000. 42:188-195.

21. Bendelac A, Savage PB, Teyton L. The biology of NKT cells. Annu Rev Immunol. 2007; 25:297-336.

22. Pleyer L, Egle A, Hartmann TN, Greil R. Molecular and cellular mechanisms of CLL: novel therapeutic approaches. Nat Rev Clin Oncol. 2009; 6:405-418.

23. Hamblin AD, Hamblin TJ. The immunodeficiency of chronic lymphocytic leukaemia. Br.Med.Bull. 2008; 87:49-62.

24. Tinhofer I, Marschitz I, Kos M, Henn T, Egle A, Villunger A, Greil R. Differential sensitivity of CD4+ and CD8+ T lymphocytes to the killing efficacy of Fas (Apo$1 / \mathrm{CD} 95)$ ligand+ tumor cells in B chronic lymphocytic leukemia. Blood. 1998; 91:4273-4281.

25. Frydecka I, Kosmaczewska A, Bocko D, Ciszak L, Wolowiec D, Kuliczkowski K, Kochanowska I. Alterations of the expression of T-cell-related costimulatory CD28 and downregulatory CD152 (CTLA-4) molecules in patients with B-cell chronic lymphocytic leukaemia. Br J Cancer. 2004; 90:2042-2048.

26. Scrivener S, Goddard RV, Kaminski ER, Prentice AG. Abnormal T-cell function in B-cell chronic lymphocytic leukaemia. Leuk Lymphoma. 2003; 44:383-389.

27. Fozza C, Corda G, Virdis P, Contini S, Barraqueddu F, Galleu A, Isoni A, Cossu A, Dore F, Careddu MG, Bonfigli S, Giannico B, Longinotti M. Derangement of 
the T-cell repertoire in patients with B-cell non-Hodgkin's lymphoma. Eur J Haematol. 2015; 94:298-309.

28. Ramsay AG, Johnson AJ, Lee AM, Gorgun G, Le DR, Blum W, Byrd JC, Gribben JG. Chronic lymphocytic leukemia $\mathrm{T}$ cells show impaired immunological synapse formation that can be reversed with an immunomodulating drug. J Clin Invest. 2008; 118:2427-2437.

29. Stenstrom M, Skold M, Ericsson A, Beaudoin L, Sidobre S, Kronenberg M, Lehuen A, Cardell S. Surface receptors identify mouse NK1.1+ $\mathrm{T}$ cell subsets distinguished by function and $\mathrm{T}$ cell receptor type. Eur $\mathrm{J}$ Immunol. 2004;34:56-65.

30. Fergusson JR, Fleming VM, Klenerman P. CD161expressing human T cells. Front Immunol. 2011; 2:36.

31. Emoto M, Zerrahn J, Miyamoto M, Perarnau B, Kaufmann SH. Phenotypic characterization of CD8(+)NKT cells. Eur J Immunol. 2000; 30:2300-2311.

32. Takahashi T, Chiba S, Nieda M, Azuma T, Ishihara S, Shibata Y, Juji T, Hirai H. Cutting edge: analysis of human V alpha $24+\mathrm{CD} 8+\mathrm{NK}$ T cells activated by alphagalactosylceramide-pulsed monocyte-derived dendritic cells. J Immunol. 2002; 168:3140-3144.

33. Fergusson JR, Smith KE, Fleming VM, Rajoriya N, Newell EW, Simmons R, Marchi E, Bjorkander S, Kang YH, Swadling L, Kurioka A, Sahgal N, Lockstone H, et al. CD161 defines a transcriptional and functional phenotype across distinct human $\mathrm{T}$ cell lineages. Cell Rep. 2014; 9:1075-1088.

34. Maggi L, Santarlasci V, Capone M, Peired A, Frosali F, Crome SQ, Querci V, Fambrini M, Liotta F, Levings MK, Maggi E, Cosmi L, Romagnani S, et al. CD161 is a marker of all human IL-17-producing T-cell subsets and is induced by RORC. Eur J Immunol. 2010; 40:2174-2181.

35. Zhang R, Li ZG, Wu MY, Zhu P, Hu YM, [Analysis of $\mathrm{T}$ cell repertoire in children with acute $\mathrm{B}$ lymphoblastic leukemia]. Zhonghua Er Ke Za Zhi. 2004; 42:66-69.

36. Guven H, Gilljam M, Chambers BJ, Ljunggren HG, Christensson B, Kimby E, Dilber MS. Expansion of natural killer (NK) and natural killer-like T (NKT)-cell populations derived from patients with B-chronic lymphocytic leukemia (B-CLL): a potential source for cellular immunotherapy. Leukemia. 2003; 17:1973-1980.

37. Tinhofer I, Rubenzer G, Holler C, Hofstaetter E, Stoecher M, Egle A, Steurer M, Greil R. Expression levels of CD38 in T cells predict course of disease in male patients with B-chronic lymphocytic leukemia. Blood. 2006; 108:2950-2956.

38. Bichi R, Shinton SA, Martin ES, Koval A, Calin GA, Cesari R, Russo G, Hardy RR, Croce CM. Human chronic lymphocytic leukemia modeled in mouse by targeted TCL1 expression. Proc Natl Acad Sci USA. 2002; 99:6955-6960. 